ВЫСОКОМОЛЕКУЛЯРНЫЕ ЭФИРЫ ЦЕЛЛЮЛОЗЫ. МЕХАНИЗМЫ ДЕЙСТВИЯ В МАТРИЧНЫХ ТАБЛЕТКАХ ПРОЛОНГИРУЮЩЕГО ДЕЙСТВИЯ. ЗАВИСИМОСТЬ ПРОФИЛЯ ВЫСВОБОЖДЕНИЯ АКТИВНОЙ СУБСТАНЦИИ ОТ МОЛЕКУЛЯРНОЙ МАССЫ И ГИДРОФИЛЬНЫХ СВОЙСТВ ПОЛИМЕРА

\author{
C.B. Трофимов
}

Пятигорский медико-фармацевтический институт - филиал ГБОУ ВПО ВолгГМУ Минздрава России, г. Пятигорск

\title{
HIGH MOLECULAR CELLULOSE ESTERS. MECHANISM \\ OF ACTION IN SUSTAINED RELEASE MATRIX TABLETS. DISSOLUTION PROFILE OF ACTIVE DRUG DEPENDING ON MOLECULAR WEIGHT AND HYDROPHILIC PROPERTIES OF POLYMERS
}

\author{
S.V. Trofimov \\ Pyatigorsk Medical and Pharmaceutical Institute - \\ a branch of Volgograd State Medical University, Pyatigorsk \\ E-mail: Trofimov_sv1980@mail.ru
}

В данной статье рассматриваются производные эфиров целлюлозы как важные компоненты при разработке пролонгированных таблетированных лекарственных форм. Изучаются современные подходы к разработке готовых лекарственных форм, основанные на технологических и физикохимических свойствах вспомогательных веществ для обеспечения пролонгирующего эффекта, а также механизм их взаимодействия $\mathrm{c}$ активной субстанцией для обоснования выбора оптимального пролонгирующего агента в соответствии с желаемым результатом. В качестве модельных пролонгирующих веществ рассматриваются различные типы эфиров целлюлозы: гидроксипропилметилцеллюлоза (ГПМЦ), гидроксиэтилцеллюлоза (ГЭЦ), изучается влияние различного молекулярного веса и гидрофильных свойств на скорость высвобождения активной субстанции из матричной таблетированной формы пролонгированного действия.

Ключевые слова: гидроксипропилметилцеллюлоза, гидроксиэтилцеллюлоза, пролонгированное высвобождение, профиль растворения.
This article reviews cellulose esters as important excipients in development of dosage forms with sustained release. We have studied modern methods of drug development, based on technological, and physical and chemical properties of excipients to provide a sustained release effect and the mechanism of interaction between active substance and excipients for justification of choice of the optimum prolonging agent in compliance with desirable result. Different cellulose esters were used as model excipients. They were hydroxypropylmethylcellulose (HPMC) and hydroxyethylcellulose (HEC). We have studied an effect of molecular weight and hydrophilic properties on dissolution rate of active substance from the tablets with sustained release.

Keywords: hydroxypropylmethylcellulose (HPMC), hydroxyethylcellulose (HEC), sustained release, dissolution profile. 
Пролонгированные

лекарственные формы занимают обширную нишу на рынке таблетированных лекарственных препаратов. На данный момент такая форма лекарственного средства по-прежнему актуальна. Об этом говорит хотя бы тот факт, что для многих препаратов пролонгированная форма стала продолжением и усовершенствованием разработанного изначально препарата с немедленным высвобождением.

В частности, для сахароснижающих препаратов можно привести в качестве примера метформин, гликлазид, глипизид, глимепирид [4].

Преимущества пролонгированной лекарственной формы зачастую очевидны: более упорядоченный прием лекарства, уменьшение количества приемов в день и соответственно меньший риск пропустить время приема (в тех случаях, когда это важно), уменьшенный риск, связанный с побочными эффектами, более равномерное и длительное действие лекарства [5, 11, 15].

Однако, необходимость поддерживать нужную скорость высвобождения в течение длительного времени (как правило, от 8 до 24 часов) предъявляет к лекарственной форме более жесткие требования в плане качества активной субстанции, вспомогательных веществ и технологического процесса $[9,11,15]$.

Современные подходы к разработке технологического процесса подразумевают проработку модели разработки оценки возможных рисков и критических точек контроля качества еще на стадии предпроектной подготовки и определения цели будущей лекарственной формы, таким образом, качество готовой лекарственной формы закладывается в неё непосредственно и начинается на стадии изучения активной субстанции и выбора оптимальных вспомогательных веществ и технологического процесса для достижения оптимальных результатов [10].

До определенного времени считалось, что вспомогательные вещества, являясь инертными, не оказывают воздействия на высвобождение лекарственного препарата, однако по мере развития биофармации, накопления экспериментальных данных было совершенно четко установлено, что даже будучи формально инертными веществами, различные наполнители, тем не менее, оказывают непосредственное влияние на свойства готовой лекарственной формы, поэтому необходимо учитывать их влияние и свойства непосредственно на стадии планирования.

Для пролонгированных лекарственных средств, несмотря на то, что прочие вспомогательные вещества будут оказывать влияние на профиль растворения, основным фактором является выбор оптимальных пролонгирующих веществ и технологии получения $[1,9,11,15,16]$.

Технологические приемы для обеспечения пролонгирующего эффекта в твердых лекарственных формах весьма различны (от пленочных покрытий до применения экструзионных процессов) $[6,8,10,15]$

Тем не менее, одними из самых популярных остаются матричные таблетки, это объясняется в первую очередь относительной простотой процесса (по сравнению с другими способами) и отсутствием дополнительного оборудования. При этом при получении матричных таблеток чаще всего используется способ прямого прессования ввиду технологических особенностей, используемых для пролонгирования вспомогательных веществ, высокая молекулярная масса которых затрудняет использование метода влажной грануляции.

Ассортимент вспомогательных веществ для матричных таблеток также весьма широк $[2,3,6,7,8,13]$ и включает в себя:

- сополимер винилпирролидона и винилацетата (коллидон SR);

- полиэтиленоксиды с высоким молекулярным весом (более 100000);

- производные крахмала (натрия крахмал гликолят, тип «С»); бомер);

- акриловые полимеры (эудрагит, кар-

- производные целлюлозы (метилцеллюлоза (МЦ), гидроксипропилметилцеллюлоза (ГПМЦ), этилцеллюлоза (ЭЦ), метилгидросиэтилцеллюлоза (МГЭЦ), гид- 
роксипропилцеллюлоза (ГПЦ), гидроксиэтилцеллюлоза (ГЭЦ)).

Используемые полимеры можно условно разделить на 2 группы - набухающие и ненабухающие.

Ненабухающие полимеры, как правило, являются нерастворимыми и регулируют профиль растворения за счет диффузии активного вещества через поры в матрице (этилцеллюлоза, коллидон SR) [3, 8, 13].

Большую группу полимеров для пролонгации составляют набухающие полимеры, например эфиры целлюлозы: ГПЦ, МЦ, МГЭЦ, ГПМЦ, ГЭЦ. Скорость высвобождения из таких матриц регулируется степенью и скоростью набухания пролонгирующего полимера, которые в свою очередь зависят от молекулярной массы и гидрофильных свойств используемого полимера.

Простая диффузия описывается уравнением Фика: скорость диффузии $\frac{d m}{d t}$ прямо пропорциональна градиенту концентрации $\frac{d c}{d x}$ площади $\mathrm{S}$, через которую осуществляется диффузия:

$$
\frac{d m}{d t}=-D S \frac{d c}{d x}
$$

где D - коэффициент диффузии, численно равный количеству вещества, диффундирующего в единицу времени через единицу площади при градиенте концентрации, равном единице. Коэффициент диффузии зависит от природы вещества и от температуры $[14,15,16]$.

При этом для полимеров с высокой молекулярной массой, обладающих высокой степенью набухания, преобладает нелинейная зависимость высвобождения (рис. 1), поскольку с увеличением степени набухания полимера скорость диффузии замедляется, так как при гидратации на поверхности образуется слой геля, регулирующий скорость высвобождения.

В общем виде зависимость можно представить следующим уравнением:

$$
C=k \sqrt{t}
$$

где $k-$ коэффициент, зависящий от природы веществ, температуры и других факторов.

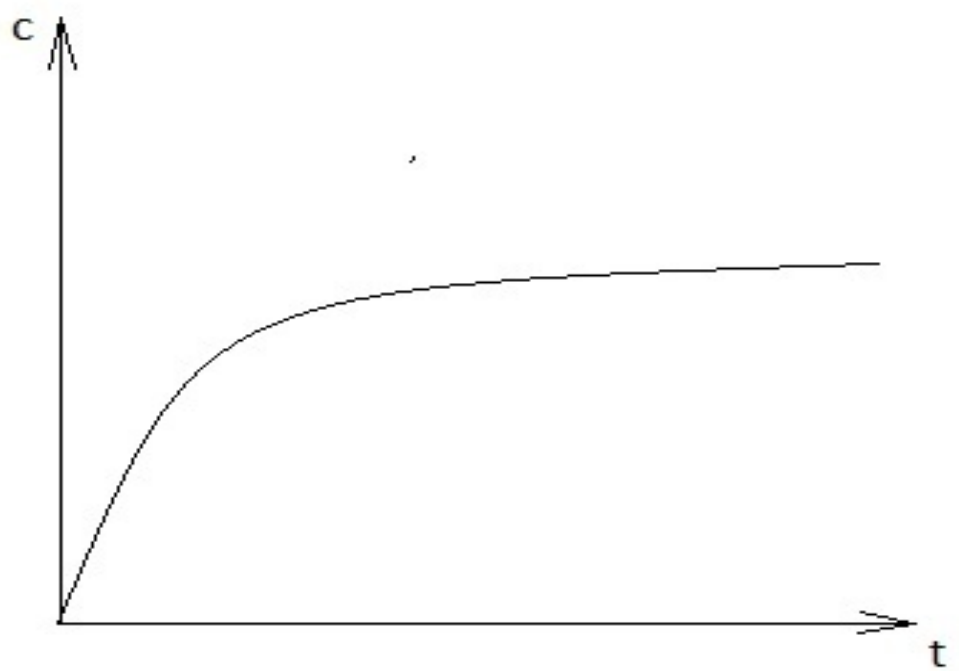

\section{Рисунок 1 - Типичный профиль скорости высвобождения активной субстанции из матрицы с высокомолекулярным полимером}

Для полимеров с низкой молекулярной массой преобладает линейная зависимость высвобождения активного вещества (рис. 2), которая обуславливается не столько набухающими свойствами полимера, кото- рые выражены слабее, чем у высокомолекулярных полимеров, сколько физическим разрушением матрицы с течением времени (эрозия). 


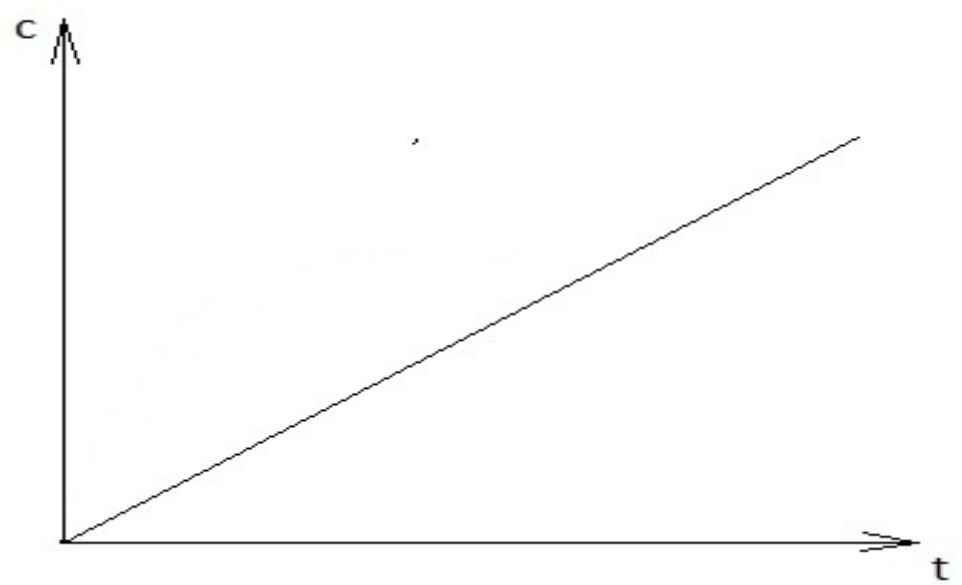

\section{Рисунок 2 - Типичный профиль скорости высвобождения активной субстанции из матрицы с низкомолекулярным полимером}

Помимо молекулярной массы и степени набухания важную роль в процессе высвобождения активного вещества будут играть гидрофильные свойства полимера, так, например гидроксиэтилцеллюлоза за счет заместителей в молекуле целлюлозы, отличных от ГПМЦ, является более гидрофильным полимером, обладает более быстрой скоростью набухания, но при этом является более проницаемой, так как слой геля менее плотный, чем для ГПМЦ, а также более растворимым полимером, склонным к более быстрому (чем ГПМЦ) разрушению структуры матрицы $[6,13]$.

В данной таблетируемой форме ГЭЦ, обладая быстрой гидратацией, играет роль солюбилизатора, поскольку обеспечивает быстрое смачивание и более длительный контакт активной субстанции с растворителем, обеспечивая более полное ее рас- творение, что является важным фактором в случае использования малорастворимой активной субстанции.

Таким образом, целью данной работы было изучить влияние молекулярного веса полимеров и различных гидрофильных свойств на профиль растворения малорастворимой активной субстанции и матричных таблеток пролонгированного действия на примере глибенкламида.

В качестве пролонгирующих полимеров использовались эфиры целлюлозы компании Ashland:

- ГПМЦ Benecel K100LV CR Pharm;

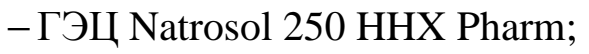

-ГЭЦ Natrosol 250 G Pharm.

Основные свойства использованных полимеров приведены в таблице 1.

\section{Таблица 1 - Свойства эфиров целлюлозы, использованных \\ в качестве пролонгирующих агентов}

\begin{tabular}{|l|c|c|c|c|}
\hline & $\begin{array}{c}\text { Номинальная вязкость } \\
\text { по Брукфильду } \\
\text { (для 2\% р-ра), мПа*с }\end{array}$ & $\begin{array}{c}\text { Средняя } \\
\text { молекулярная } \\
\text { масса }\end{array}$ & $\begin{array}{c}\text { Насыпная } \\
\text { масса, } \\
\text { г/см }\end{array}$ & $\begin{array}{c}\text { Поверхностное } \\
\text { натяжение, } \\
\text { мН/м }\end{array}$ \\
\hline $\begin{array}{l}\text { Benecel } \\
\text { K100LV CR Pharm }\end{array}$ & 100 & 164000 & 0,53 & 50 \\
\hline $\begin{array}{l}\text { Natrosol } \\
\text { 250 HHX Pharm }\end{array}$ & 100000 & 1300000 & 0,7 & 67 \\
\hline $\begin{array}{l}\text { Natrosol } \\
\text { 250 G Pharm }\end{array}$ & 350 & 300000 & 0,62 & 67 \\
\hline
\end{tabular}

Таблетки глибенкламида 5 мг, спрессованные с помощью ротационного табле- точного пресса Bosch XSPress (усилие прессования и другие параметры замеря- 
лись с помощью программного обеспечения таблеточного пресса).

Номинальная масса таблеток 250 мг. (допустимые отклонения $\pm 7,5 \%$ )

Пуансоны D=9мм, двояковыпуклые.

Все сравнительные образцы таблеток получали при одинаковых параметрах про- цесса, для оценки влияния свойств полимеров на профиль пролонгации.

Для определения профиля высвобождения использовался метод высокоэффективной жидкостной хроматографии (ВЭЖХ), прибор ВЭЖХ Agilent 1200

\section{Таблица 2-Составы с полимерами различного молекулярного веса}

\begin{tabular}{|c|c|c|}
\hline & Состав 1 & Состав 2 \\
\hline Глибенкламид & \multicolumn{2}{|c|}{$5 \mathrm{мг}$} \\
\hline МКЦ Avicel РН200 & \multicolumn{2}{|c|}{$105 \mathrm{мг}$} \\
\hline Кальция гидрофосфат дигидрат & \multicolumn{2}{|c|}{$50 \mathrm{мг}$} \\
\hline ГПМЦ К100LV CR Pharm & \multicolumn{2}{|c|}{$25 \mathrm{M \Gamma}$} \\
\hline ГЭЦ Natrosol 250 HНX Pharm & 50 мг & - \\
\hline ГЭЦ Natrosol 250 G Pharm & - & $50 \mathrm{M \Gamma}$ \\
\hline Коповидон & \multicolumn{2}{|c|}{$10 \mathrm{мг}$} \\
\hline Кремния диоксид коллоидный & \multicolumn{2}{|c|}{$2,5 \mathrm{M \Gamma}$} \\
\hline Магния стеарат & \multicolumn{2}{|c|}{$2,5 \mathrm{M \Gamma}$} \\
\hline Вес таблетки & \multicolumn{2}{|c|}{$250 \mathrm{M \Gamma}$} \\
\hline
\end{tabular}

Все таблетки были получены методом прямого прессования с одинаковыми показателями по прочности для оценки влияния молекулярного веса полимера на профиль растворения.

Результаты теста растворения представлены на рисунке 3.

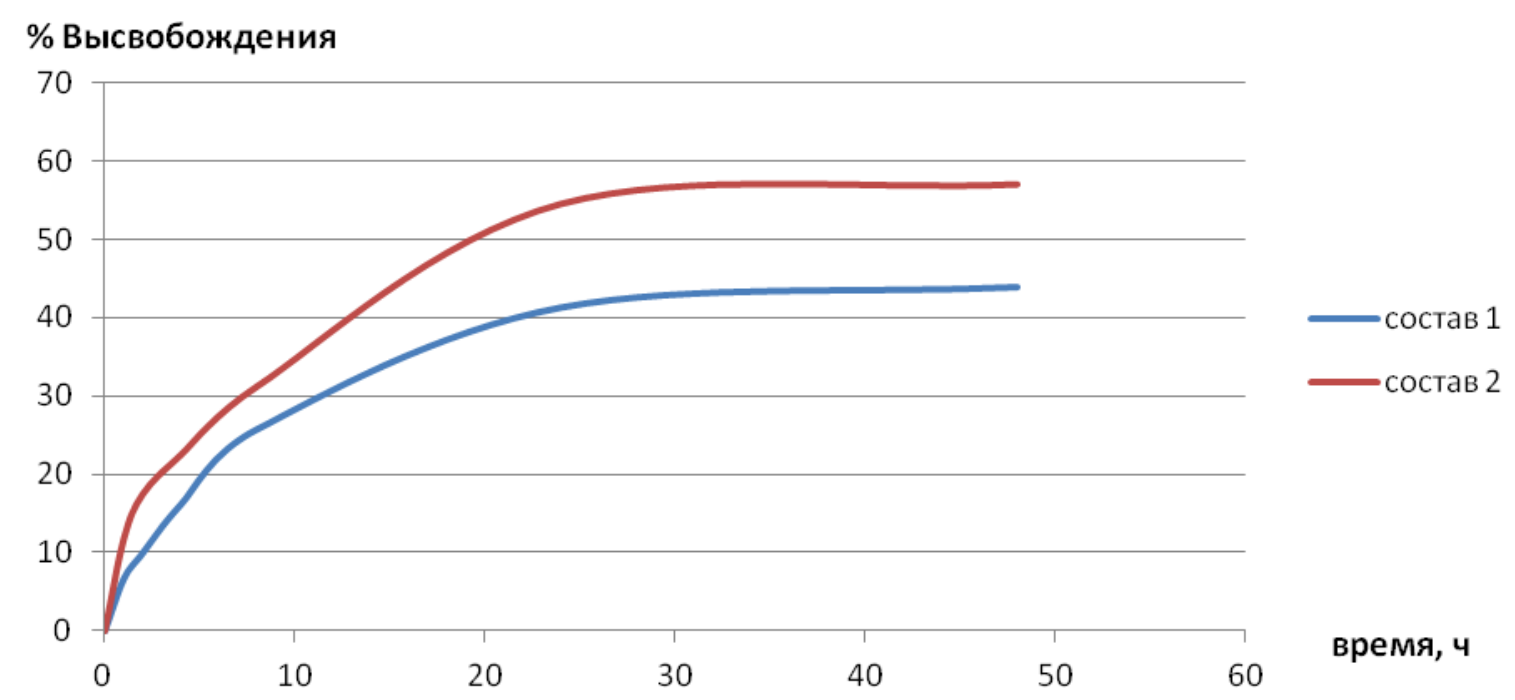

Рисунок 3 - Профили растворения сравниваемых составов с различными типами гидроскиэтилцеллюлозы

Несмотря на то, что оба сравниваемых состава показали неудовлетворительные результаты по показателю растворение, тем не менее, можно отметить, что полимеры с разным молекулярным весом, взятые в эквивалентных количествах, дают разные результаты по скорости высвобождения активной субстанции. 
Таблица 3 - Составы с полимерами различного молекулярного веса

\begin{tabular}{|c|c|c|c|}
\hline & Состав 3 & Состав 4 & Состав 5 \\
\hline Глибенкламид & \multicolumn{3}{|c|}{$5 \mathrm{M \Gamma}$} \\
\hline Лактозы моногидрат & $142,5 \mathrm{M \Gamma}$ & 155 мг & $180 \mathrm{M \Gamma}$ \\
\hline ГПМЦ К100LV CR Pharm & \multicolumn{3}{|c|}{$25 \mathrm{M \Gamma}$} \\
\hline ГЭЦ Natrosol 250 G Pharm & $62,5 \mathrm{M \Gamma}$ & 50 мГ & $25 \mathrm{M \Gamma}$ \\
\hline Коповидон & \multicolumn{3}{|c|}{$10 \mathrm{M \Gamma}$} \\
\hline Кремния диоксид коллоидный & \multicolumn{3}{|c|}{$2,5 \mathrm{M \Gamma}$} \\
\hline Магния стеарат & \multicolumn{3}{|c|}{$2,5 \mathrm{M \Gamma}$} \\
\hline Вес таблетки & \multicolumn{3}{|c|}{250 мГ } \\
\hline
\end{tabular}

В данном случае изучалось влияние количества полимера на профиль растворения, при этом ГПМЦ использовалась в одинаковом количестве во всех составах, тогда как количество более гидрофильного полимера (ГЭЦ) использовалось соответ- ственно $25 \%, 20 \%$ и $10 \%$ от состава таблетки. Количество полимера при уменьшении компенсировалось эквивалентным количеством наполнителя - лактозы моногидрата.

Результаты теста растворения представлены на рисунке 4.

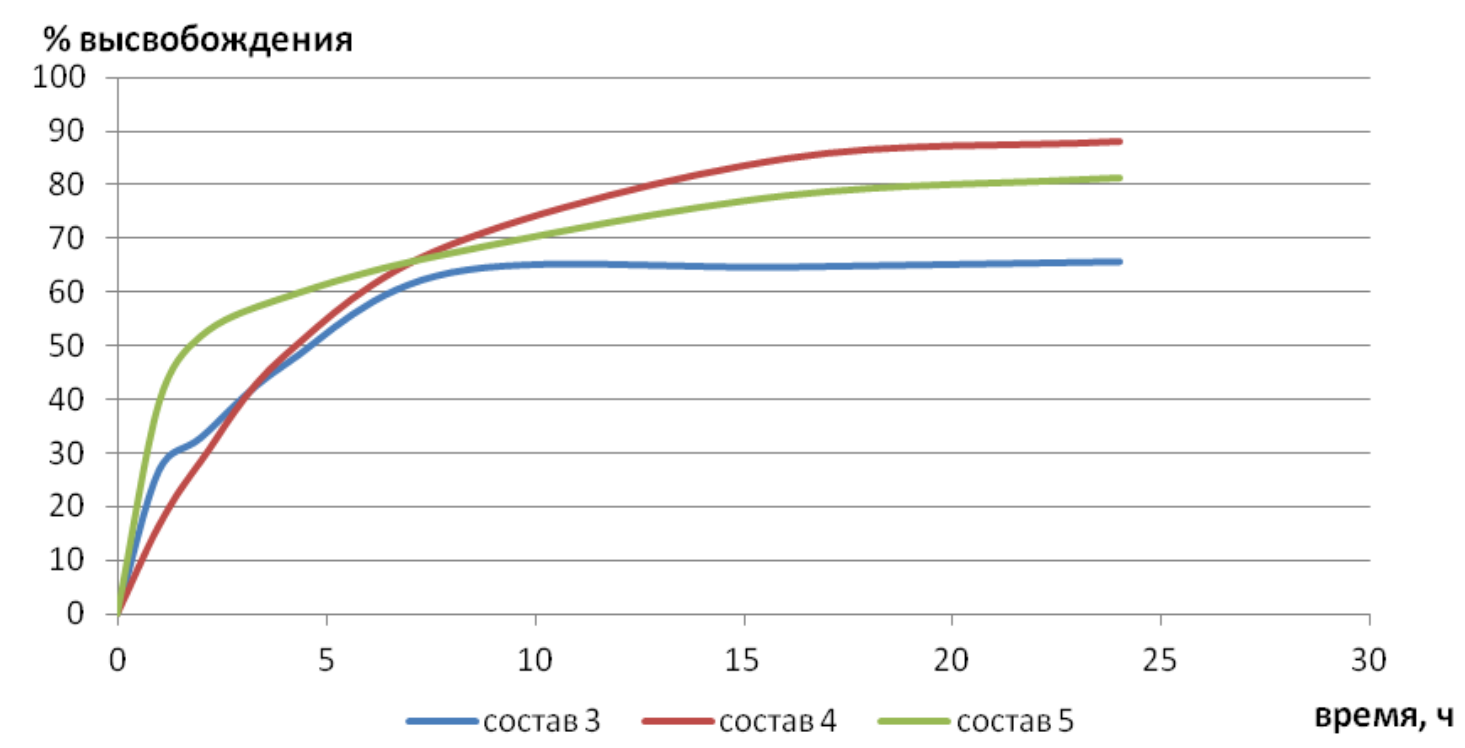

\section{Рисунок 4 - Профили растворения сравниваемых составов с различным содержанием гидроксиэтилцеллюлозы}

По полученным результатам можно отметить, что состав 3 (по сравнению с составом 4) показывает более быструю скорость растворения, несмотря на большее количество пролонгирующего полимера, что можно объяснить его гидрофильными свойствами, поскольку более быстрая абсорбция воды способствует более быстрому растворению активной субстанции в первые часы растворения, однако в дальнейшем можно заметить постепенное замедление высвобождения, так как большее количество полимера способствует образо- ванию более толстого слоя геля на поверхности, что затрудняет высвобождение активного вещества.

Состав 5 показывает в целом более быстрое высвобождение по сравнению с другими, что можно объяснить меньшим количеством пролонгирующих агентов, однако также можно заметить постепенное замедление высвобождения (по сравнению с составом 4), что можно объяснить тем, что в составе 4 используется большее количество гидрофильного полимера, которое выступает также солюбилизатором и 
обеспечивает более полное растворение активной субстанции.
В целом профиль растворения состава 4 наиболее близок желаемому и может быть выбран как основной.

Таблица 4-Составы с различным соотночением пролонгирующих полимеров

\begin{tabular}{|l|c|c|}
\hline & Состав 4 & Состав 6 \\
\hline Глибенкламид & \multicolumn{2}{|c|}{5 мг } \\
\hline Лактозы моногидрат & \multicolumn{2}{|c|}{155 мг } \\
\hline ГПМЦ К100LV CR Pharm & 25 мг & 37,5 мг \\
\hline ГЭЦ Natrosol 250 G Pharm & 50 мг & 37,5 мг \\
\hline Коповидон & \multicolumn{2}{|c|}{10 мг } \\
\hline Кремния диоксид коллоидный & \multicolumn{2}{|c|}{2,5 мГ } \\
\hline Магния стеарат & \multicolumn{2}{|c|}{2,5 мг } \\
\hline Вес таблетки & \multicolumn{2}{|c|}{$\mathbf{2 5 0}$ мг } \\
\hline
\end{tabular}

В данном примере изучалось различное соотношение пролонгирующих полимеров и влияние их гидрофильных свойств на профиль растворения. В составе 4 использовалось соотношение полимеров ГПМЦ:
ГЭЦ 1:2. В составе 6 использовалось соотношение полимеров $1: 1$.

Результаты теста растворения представлены на рисунке 5.

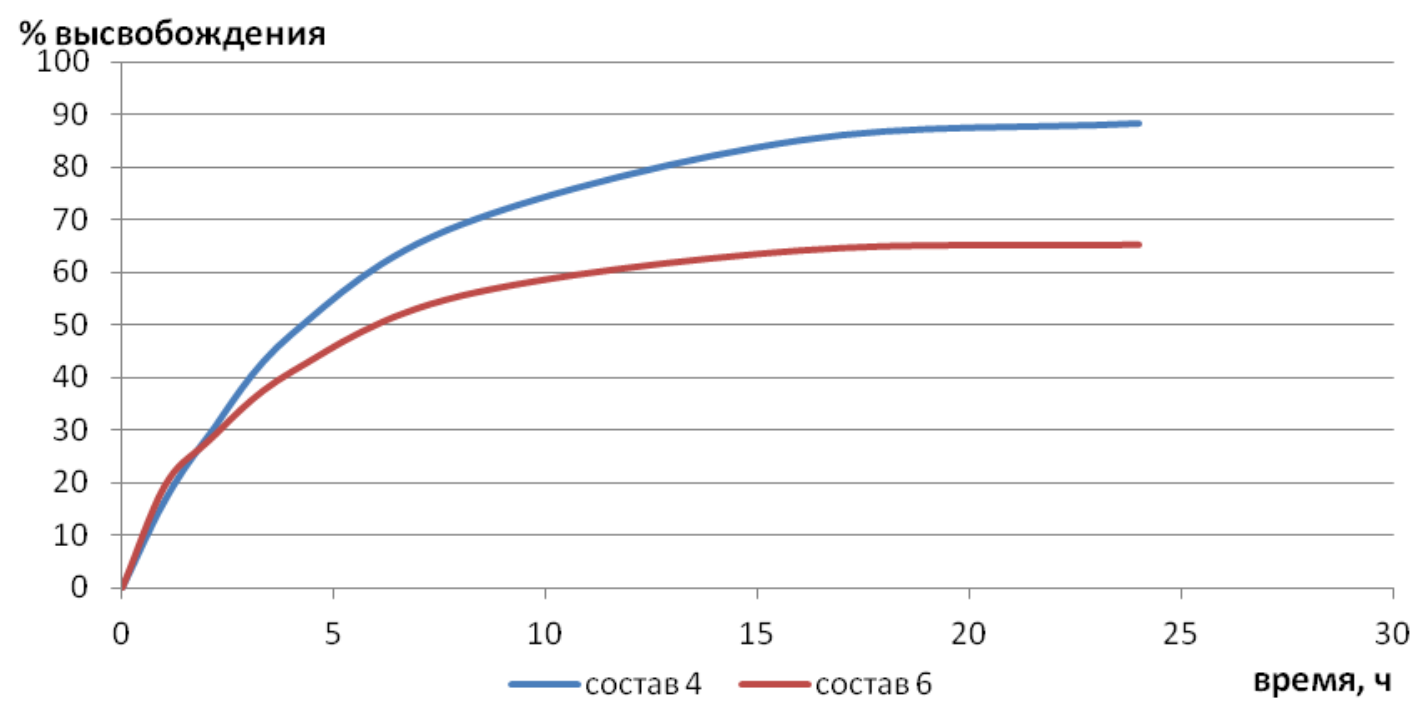

Рисунок 5 - Результаты теста растворения

По полученным результатам можно отметить, что в первые 2 часа растворения результаты практически идентичны, однако в дальнейшем состав 4 показывает более быстрое растворение и высвобождение активного вещества. Это можно объяснить 2 причинами:

- в составе 4 содержится большее количество ГЭЦ, которая, выступая в роли солюбилизатора, обеспечивает более полное растворение и высвобождение активной субстанции;

- вместе с этим, в составе 6 уменьшенное количество ГЭЦ было компенсировано ГПМЦ, которая является более гидрофобным веществом и в данном случае способствует замедлению высвобождения (по сравнению с составом 4).

\section{Выводы}

В результате проведенных экспериментальных исследований полученные данные показывают, что при выборе полимеров для пролонгации высвобождения безусловно важ- 
ную роль играет молекулярный вес и количество полимера, однако также важно учитывать гидрофильные свойства полимеров (в случае использования эфиров целлюлозы) и их влияние на активную субстанцию, поскольку, как показывают результаты, они также влияют на профиль растворения и изменение соотношения более гидрофильного полимера к более гидрофобному может повлиять на профиль высвобождения (особенно в случае малорастворимых активных веществ), что необходимо учитывать при планировании дизайна эксперимента, поскольку знание и понимание свойств вспомогательных веществ помогает выбрать наиболее оптимальные и сократить время разработки готовой лекарственной формы.

\section{Библиографический список}

1. Алексеев, К.В. Полимеры для фармацевтической технологии: учеб. пособие / К.В. Алексеев, И.А. Грицкова, С.А. Кедик; под ред. С.А. Кедика. - М.,: 2011. - 512 с.

2. Бенецел. Высокоочищенная метилцеллюлоза и метилгидроксипропилцеллюлоза. Физические и химические свойства. Ashland. - Режим доступа: www.ashland.com

3. Бюлер, Ф. Коллидон. Поливинилпирролидон для фармацевтической промышленности.BASF: пер с англ. / Ф. Бюлер; под ред. К.В Алексеева. - М., 2001. - 310 с.

4. Машковский М. Д. Лекарственные средства. - 16-е изд., перераб., испр. и доп. - М.: Новая волна, 2012. - 216 с.

5. Муравьёв И.А. Технология лекарств. - 3-е изд., перераб. и доп. - М.: Медицина, 1980. - T. 1. -395 c.

6. Натросол. Гидроксиэтилцеллюлоза. Физические и химические свойства. Ashland. Режим доступа: www.ashland.com

7. Натрия крахмал гликолят, тип C (JRS). - Режим доступа: www.rettenmaier.ru

8. Тенцова, А.И., Ажгихин И.С. Лекарственная форма и терапевтическая эффективность лекарств. М.: Медицина, 1974. 336 с.

9. Фармацевтическая разработка: пер. с англ. / А.В. Александров, Н.В. Дынька, В.А. Жулинский и др. - Киев: Виалек, 2008. - 40 с.

10. Фармацевтические и медико-биологические аспекты лекарств / И.М. Перцев и др. Харьков: УкрФА, 1999. - Т. 1.-461 с.

11. Фармацевтические вспомогательные вещества // Ashland. Технический бюллетень. - 23 с. - Режим доступа: www.ashland.com.

12. Фармацевтическая технология. Твердые лекарственные формы: учеб. пособие / К.В. Алексеев и др.; под ред. С.А. Кедика. - М. : Ин-т фармацевт. технологий, 2011. - 661 с

13. Чуешов В.И. Промышленная технология лекарств. - Харьков: НФАУ, 2002. - Т. 2. $-716 \mathrm{c}$

14. Bader R.A., Putnam D.A. Engineering polymer systems for improved drug delivery. Wiley, 2014. $492 \mathrm{p}$

15. DOW Chemical. Polyox. - Режим доступа: www.dow.com

16. Rowe, R.C. Handbook of pharmaceutical excipients. $-6^{\text {th }}$ edition/ R.C. Rowe, P.J. Sheskey, M. E. Quinn// Pharmaceutical press. - 2009.

Трофимов Сергей Валерьевич - аспирант Пятигорского медико-фармачевтического института - филиала ГБОУ ВПО ВолгГМУ Минздрава России. Область научных интересов: технология твердых лекарственных форм, лекарственные формы с пролонгированным высвобождением. E-mail: Trofimov_sv1980@mail.ru. 